\title{
INORGANIC LEAD TOXICOLOGY
}

\author{
Jiří Patočka ${ }^{1,2}$, Karel Černý2 \\ Purkyně Military Medical Academy in Hradec Králové: Department of Toxicology ${ }^{1}$; University of South Bohemia, České \\ Budějovice, Faculty of Health and Social Care: Department of Radiology²
}

\begin{abstract}
Summary: Lead is a health hazard for all humans. Especially children under the age of six are most at risk for lead poisoning. Lead toxicity causes hematological, gastrointestinal, and neurological dysfunction. Symptoms are usually noted with blood lead greater than 2 micromoles/L. Severe or prolonged exposure may also cause chronic nephropathy, hypertension, and reproductive impairment. Lead inhibits some enzymes, alters cellular calcium metabolism, stimulates synthesis of binding proteins in kidney, brain, and bone, and slows down nerve conduction. Acute lead poisoning is relatively infrequent and results from ingestion of acid soluble lead compounds or inhalation of lead vapors but chronic exposure to low levels of the metal is still a public health issue, especially among some minorities and socioeconomically disadvantaged groups. Lead has been used since prehistoric times, and has become widely distributed and mobilized in the environment. Exposure to and uptake of this non-essential element have consequently increased. Both occupational and environmental exposures to lead remain a serious problem in many developing and industrializing countries and a public health problem of global dimensions.
\end{abstract}

Key words: Inorganic lead; Toxicity profile; Toxicokinetics, Toxicodynamics, Animal and human studies; Mecjanism of toxic action; Treatment

\section{Introduction}

Lead is a natural heavy metal that exists in elemental, inorganic, and organic forms. This forging metal has been mined and used in industry and in household products for centuries. Lead is present in trace amounts in all soils, water, and foods. Metallic lead is soft, ductile, blue-gray in color, and is highly resistant to corrosion. The melting point of lead is $327^{\circ} \mathrm{C}$. These properties, along with the poor ability of lead to conduct heat and electricity, probably contributed to the early discovery and persistent use of lead by humans. Lead pigments, for example, have been used in paints for more than 40,000 years, and lead utensils and artifacts, dating back 8000 years, have been recovered from Mediterranean excavation sites. Currently, lead is used in more than 900 occupations and hobbies, including mining, smelting, refining, battery manufacturing, soldering, electrical wiring, home demolition and construction, painting, ceramic glazing, and the making of stained glass (1).

The dangers of lead toxicity, the clinical manifestations of which are known as plumbism, have been known since ancient times. In the second century B.C., the Greek physician Discorides noted that lead makes the "mind give way." In the first century B.C., Marcus Vitruvius Pollio, the father of architecture, recommended that clayware replace all the lead-based water pipeline system in the Roman Empire be- cause "lead destroyed the vigor of the blood." The twentieth century has seen both the greatest-ever exposure of the general population to lead and an extraordinary amount of new research on lead toxicity. Today, lead toxicity is well documented and is recognized as a major environmental health risk throughout the world. Lead affects humans and animals of all ages, but the affects of lead are most serious in young children (64). The aim of this review is to deal with inorganic divalent lead compounds, not tetravalent organic derivatives of this metal. The tetravalent organic form of lead is generally more toxic than the divalent, inorganic form, and its distribution in organisms, metabolism and mechanism of biological action is different.

\section{Environmental Sources of Lead}

Populations are exposed to lead chiefly via paints, cans, plumbing fixtures, and leaded gasoline. The intensity of these exposures, while recently decreased by regulatory actions, remains high in some segments of the population because of the deterioration of lead paint used in the past and the entrainment of lead from paint and vehicle exhaust into soil and house dust. Agricultural land contains on the average $10 \mathrm{mg} \mathrm{Pb} / \mathrm{kg}$. Generally, inorganic lead is regarded as a slow migratory metal as a consequence of poor solubility of lead salts present in soil. Recently was found that 
$\mathrm{Pb}^{2+}$ is able to produce well soluble salts with some natural acids (humic and fulvic acids, some amino acids), which changes our knowledge of lead movement in nature (7). Many other environmental sources of exposure exist, such as leafy vegetables grown in lead-contaminated soil, improperly glazed ceramics, lead crystal, and certain herbal folk remedies. The amount of lead in atmosphere is very variable. In areas with low pollution a content of lead is 0.005 $-0.3 \mu \mathrm{g} / \mathrm{m}^{3}$, in heavy fumes and industrial areas $0.2-5.0$ $\mu \mathrm{g} / \mathrm{m}^{3}$. Many industries, such as battery manufacturing, demolition, painting and paint removal, and ceramics, continue to pose a significant risk of lead exposure to workers and surrounding communities. New research on lead toxicity has been stimulated by advances in toxicology and epidemiology as well as by a shift of emphasis in environmental toxicology.

\section{Toxicokinetics}

Elemental lead and inorganic lead compounds are absorbed through ingestion or inhalation. Pulmonary absorption is efficient, particularly if airborne lead particle diameters are 1 micrometre generally are completely absorbed by the alveoli. Gastrointestinal absorption of lead is less effective and depends on a number of factors, eg, the presence of food in the stomach, the concentration of lead ingested, the nutritional status of the patient, and the age of the patient. Lead absorption rates may increase with iron, zinc, and calcium deficiencies. Children are at the highest risk for toxicity because they absorb up to 50 percent of the amount of lead ingested, whereas adults absorb only about 10 to 20 percent.Transdermal absorption is minimal for inorganic lead (17).

Lead is absorbed into blood plasma, where it equilibrates rapidly with extracellular fluid, crosses membranes such as the blood-brain barrier and the placenta, and accumulates in soft and hard tissues. In the blood, around 95 to 99 percent of lead is sequestered in red cells, where it is bound to hemoglobin and other components. Lead deposition in erythrocytes and soft tissues is responsible for most of the toxic effects of the metal. The half-life of lead differs for each of the compartments, ranging from 25-40 days in erythrocytes, 40 days in soft tissues, and as many as 28 years in bone. Bone lead accounts for more than $95 \%$ of the lead burden in adults and $70 \%$ of the burden in children. Lead is commonly incorporated into rapidly growing bones, such as the tibia, femur, and radius, where it competes with calcium and may exert toxic effects on skeletal growth. Bone acts as a reservoir for lead in the same way that it acts as a reservoir for calcium. The body may mobilize its lead stores during periods of stress, fever, hyperthyroidism, prolonged immobilization, pregnancy, and lactation. Lead that is not retained by the body is excreted unchanged in urine (65-75\%) and in bile (25-30\%). Lead also appears in hair, nails, sweat, saliva, and breast milk (36).

\section{Toxicodynamics}

The toxicity of lead is probably related to its affinity for cell membranes and mitochondria, as a result of which it interferes with mitochondrial oxidative phosphorylation and sodium, potassium, and calcium ATPases (21). Lead impairs the activity of calcium-dependent intracellular messengers and of brain protein kinase $C$ (31). In addition, lead stimulates the formation of inclusion bodies that may translocate the metal into cell nuclei and alter gene expression (11).

Lead poisoning results from the interaction of the metal with biological electron-donor groups, such as the sulfhydryl groups, which interferes with a multitude of enzymatic processes. Lead also interacts with essential cations, particularly calcium, iron, and zinc; it interferes with the sodium-potassium-adenosine triphosphate $\left(\mathrm{Na}^{+} / \mathrm{K}^{+}-\mathrm{ATP}\right)$ pump; and it alters cellular and mitochondrial membranes, thereby increasing cellular fragility (62). Additionally, lead inhibits pyrimidine-5'-nucleotidase and alters other nucleotide functions. Lead interferes with many enzyme systems of the body, thereby affecting the function of virtually every organ. Clinical manifestations of lead toxicity include symptoms referable to the central nervous system, the peripheral nervous system, the hematopoietic system, the renal system, and the gastrointestinal system. Children exposed to lead may experience devastating consequences because of the effects of lead on the developing brain (23).

\section{Carcinogenicity of Lead}

The carcinogenic potential of lead has been demonstrated in rats and mice by several investigators (35). The most characteristic cancer response is bilateral renal carcinoma. Azar et al. (6) administered low concentration of lead acetate in food to rats for 2 years. No renal tumors were reported in the control groups but increased renal tumor incidence has been observed in animal fed diet with high $\mathrm{Pb}$ content (from 1000 to 2000 ppm). Kasprzak et al. (25), in investigating the interaction of dietary calcium on lead carcinogenicity, fed $1 \%$ lead acetate $(8500 \mathrm{ppm} \mathrm{Pb})$ to male Sprague-Dawley rats in the diet for 79 weeks. The major part of the rats surviving $(29 / 30)$ in this treatment group beyond 58 weeks, $44.8 \%$ had renal tumors. Four rats had adenocarcinomas and the remainaing nine had adenomas. As a part of a study to determine interactions between sodium nitrite, ethyl urea and lead, male Sprague-Dawley rats were given lead acetate in their drinking water for 76 weeks (27). The concentration of lead was $2600 \mathrm{ppm}$. No kidney tumors were detected among the 10 control rats. Thirteen of 16 ( $81 \%)$ lead-treated rats had renal tubular carcinoma; three tumors were detected at 72 weeks and the remainder detected at the termination of the study. Very similar results were obtained by Van Esch and Kroes (58) in mice and hamsters.

Regarding human carcinogenicity data of lead, the situation is not so clear as in animal experiments.Some stu- 
dies $(18,39)$ did not find any association between exposure and cancer mortality. Selevan et al. (51), in their retrospective cohort mortality study of primary lead smelter workers, found a slight decrease in the total cancer mortality. Cooper and Gaffey (15) and Cooper (14) performed a cohort mortality study of battery plant workers and lead smelter workers. They found statistically significant excesses for total cancer mortality, stomach cancer, and lung cancer in the battery plant workers. Although similar excesses were observed in smelter workers, they were not statistically significant. Later works and meta-analysis studies show a significant excess risk of overall cancer, stomach cancer, lung cancer, and bladder cancer, with relative risk ratios and $95 \%$ confidence intervals respectively. The relative risk for kidney cancer was also high, but did not reach significance $(3,19)$. Recent studies show that inorganic lead induces a concentration- and time-dependent increase in DNA synthesis, without causing any cytotoxicity. Flow cytometric analysis shows that lead was able to stimulate the cell cycle transition from the $\mathrm{G} 0 / \mathrm{G} 1$ phase to the $\mathrm{S} / \mathrm{G} 2$ phase, resulting in increased percentage of cells in the latter phase. Western blot analyses show that lead induces translocation of protein kinase $\mathrm{C}\left(\mathrm{PKC}_{\mathrm{alpha}}\right)$ from the cytosolic to the particulate fraction, with a concomitant increase in PKC enzyme activity (32). Inorganic lead also activates mitogen-activated protein kinase (MAPK) cascade (31). Stimulation of DNA synthesis by lead in astrocytoma cells may be of interest in light of the observed association between exposure to lead and an increased risk of astrocytomas (13).

\section{Laboratory Profile Intoxication}

Because lead is a multiorgan toxin, consider the diagnosis of lead poisoning in patients presenting with multisystem disease (49). Regular measurement of blood lead in lead-exposed workers and the maintenance of blood lead levels below $1.9 \mu \mathrm{mol} / \mathrm{L}$ is advised (47). Lead-associated anemia is usually normocytic and normochromic and may be accompanied by basophilic stippling. Lead-induced peripheral demyelination is reflected by prolonged nerve conduction time and subsequent paralysis, usually of the extensor muscles of the hands and feet. An increased density at the metaphyseal plate of growing long bones ("lead lines") can develop in children and resemble those seen in rickets (9). Children with high-level lead exposure sometimes develop Fanconi's syndrome, pyuria, and azotemia (5). Adults chronically exposed to lead can develop elevated serum creatinine levels, decreased creatinine clearance rates, and chronic changes and intranuclear inclusion bodies (detected at renal biopsy) (30).

\section{Clinical Profile Intoxication}

Symptomatic lead poisoning in childhood generally develops at blood lead levels exceeding $3.9 \mu \mathrm{mol} / \mathrm{L}$ and is cha- racterized by abdominal pain and irritability followed by lethargy, anorexia, anemia, ataxia, and slurred speech (47). Convulsions, coma, and death due to generalized cerebral edema and renal failure occur in the most severe cases (42). Subclinical lead poisoning (blood lead level >1.4 $\mu \mathrm{mol} / \mathrm{L}$ ) can cause mental retardation and selective deficits in language, cognitive function, balance, behavior, and school performance despite the lack of discernible symptoms (28). Epidemiologic studies regarding lead's effect on the intellectual function of children indicate that cognition is probably impaired in a dose-related fashion at blood lead levels well below $1.4 \mathrm{micomol} / \mathrm{L}$ and that no threshold for this effect is likely to exist above the lowest measurable blood lead level of $0.05 \mu \mathrm{mol} / \mathrm{L}$. The impact is greatest when the exposure is of long duration and when it takes place around the age of 2 years.

In adults, symptomatic lead poisoning usually develops when blood lead levels exceed $3.9 \mu \mathrm{mol} / \mathrm{L}$ for a period of weeks and is characterized by abdominal pain, headache, irritability, joint pain, fatigue, anemia, peripheral motor neuropathy, and deficits in short-term memory and the ability to concentrate. Some individuals develop these symptoms and signs at lower blood lead levels 1.9 to $3.9 \mu \mathrm{mol} / \mathrm{L}$ and/or with briefer periods of exposure. Chronic subclinical lead exposure is associated with interstitial nephritis, tubular damage, hyperuricemia, and a decline in glomerular filtration rate and chronic renal failure. Epidemiologic evidence also suggests that blood lead levels in the range of 0.34 to $1.7 \mu \mathrm{mol} / \mathrm{L}$ are associated with increases in blood pressure, decreases in creatinine clearance, and decrements in cognitive performance that are too small to be detected as a lead effect in individual cases but nevertheless may contribute significantly to the causation of chronic disease (50).

An additional issue for both children and adults is whether lead that has accumulated in bone and lain dormant for years can pose a threat later in life, particularly at times of increased bone resorption such as pregnancy, lactation, and senile osteoporosis. Elevation of the bone lead level appears to be a risk factor for anemia and hypertension. Hyperthyroidism has been reported to cause lead toxicity in adults by mobilizing stores of bone lead acquired during childhood (26). Genetic polymorphisms of the gene that codes for aminolevulinic acid dehydratase, a critical enzyme in the production of heme, may confer differences in susceptibility to lead retention and toxicity. Perhaps 15 percent of Caucasians have a variant form of this gene (53).

\section{Hematologic Effects}

The best-known toxic effect of lead is the effect on heme synthesis. Lead inhibits delta aminolevulinic acid dehydrase (delta-ALAD) and ferrochelatase (heme-synthetase) (65). As a result, delta-ALAD cannot be converted into porphobilinogen nor can iron be incorporated into the protoporphyrin ring. Therefore, heme synthesis is reduced. 
Because heme is important for the function of the cytochrome system and cellular respiration, lead poisoning has tremendous impact on the entire organism (24). Lead also inhibits the $\mathrm{Na}^{+} / \mathrm{K}^{+}$-ATP pump and attaches to the red blood cell membranes, leading to their lysis.

- Mild poisoning - Normochromic microcytic anemia

- Moderate poisoning - Moderate, hypochromic, microcytic anemia and hemolysis with pallor

- Severe poisoning - Significant anemia, basophilic stippling, hemolysis, pallor, tachycardia, and shock

\section{Neurologic Effects}

Lead affects the central nervous system by multiple different mechanisms, most of which are unexplored. In the brain, lead is known to alter the function of cellular calcium and inactivate the blood-brain barrier (22). These alterations result in leakage of proteinaceous fluid and brain edema, which affects all parts of the CNS, predominantly the cerebellum and the occipital lobes. Lead-induced cerebral edema is manifested initially by headaches, clumsiness, vertigo, and ataxia, followed by seizures, coma, mortality, or recovery with permanent neurologic loss. Lead also impairs the function of several protein kinases and neurotransmitters. In the peripheral nervous system, lead poisoning causes segmental demyelination of motor neurons and destruction of Schwann cells, resulting in motor neuron dysfunction.

- Mild poisoning - Is characterised by fatigue, loss of interest in play and leisure activity, mood disorders, irritability, aggressive behavior, sleep disturbances and decreased libido. Further by irritable behavior, impaired cognition and impaired motor skills.

- Moderate poisoning - Is accompanied by headache, fatigue, insomnia, dizziness, tremors, hyperreflexia and numbness of the lower extremities and peripheral neuropathies.

- Severe poisoning - Encephalopathy that may occur with or without cerebral edema, manifested by stupor and coma with posturing and convulsions, increased intracranial pressure headaches with vomiting, lethargy alternating with lucidity, bizarre and aggressive behavior, clumsiness, loss of coordination, ataxia, altered sensatium, seizures, and uncounsciousness.

\section{Gastrointestinal Effects}

Lead causes contractions of the smooth muscle lining of intestinal walls (20), leading to strong, unsufferable, colic abdominal pains (lead colic). Anorexia, diarrhea, and constipation are also present.

- Mild poisoning - Anorexia, constipation, intermittent severe abdominal pain

- Moderate poisoning - Abdominal pain, anorexia and weight loss, constipation, diarrhea, volume depletion

- Severe poisoning - Abdominal wall rigidity and severe ab- dominal pain; vomiting and diarrhea with very extensive fluid losses, leading to circulatory collapse.

\section{Renal Effects}

Lead nephropathy develops because of the inhibitory effects of lead on cellular respiration (40). Lead causes a generalized dysfunction of proximal, tubular, energy-dependent functions, manifesting as a Fanconilike syndrome with aminoaciduria, glycosuria, and phosphaturia. While this effect generally is limited and reversible by chelation, chronic industrial exposure to lead has been associated with an irreversible interstitial nephropathy. This chronic nephropathy may result in hyperuricemia with gout, called saturnine gout.

- Mild poisoning - Reversible aminoaciduria which can appear especially in children and hypertension, commonly noted in adults.

- Moderate poisoning - Progressive interstitial fibrosis, persistent Fanconi-like syndrome, hyperuricemia and gout. - Severe poisoning - Interstitial fibrosis with renal failure

\section{Other Effects}

Lead has negative effects on the reproductive system, causing low sperm count and abnormal sperm morphology in men and infertility (4), menstrual irregularity, spontaneous abortion, and stillbirths in women (41). In children, lead impairs the release of human growth hormone and insulin growth factor and interferes with skeletal calcium and cyclic adenosine monophosphate (cAMP) functions, resulting in abnormalities of bone growth. Chronic exposure to lead also may result in reduced thyroid function. Rarely, acute lead poisoning results in hepatitis, pancreatitis, or cardiac dysfunction (59).

\section{Differences Between Acute and Chronic Intoxication}

\section{Acute Intoxication}

Acute lead poisoning is very rare. In children, acute massive lead poisoning generally is due to the cumulative effects of continued exposure to small amounts of lead, culminating in an acute life-threatening presentation. Most commonly, patients present with symptoms relating to the CNS, the GI tract, and the hematologic system. Anorexia, constipation, and intermittent abdominal pain, common in mild-to-moderate lead toxicity, also may be observed in severe toxicity and usually precede encephalopathy. Many children are observed vomiting and are lethargic a few days prior to the onset of encephalopathy. Lead encephalopathy is characterized by headaches, clumsiness, vertigo, and ataxia, followed by seizures and coma. Abdominal pain is intense. Vomiting and diarrhea may be severe enough to result in hypovolemic shock. Anemia due to hemolysis and iron deficiency may be evident. Renal failure may en- 
sue (44). Acute lead poisoning in adults also is extremely rare (45).

\section{Chronic Intoxication}

Although population exposure to lead has declined, chronic lead toxicity remains a major public health problem in many countries affecting millions of children and adults. The lead at low levels affects brain microvasculature. Electron microscopically and biochemically detectable changes are associated with disturbances in blood-brain barrier function. In spite of intensive reasearch, many unanswered questions remain unknown, as for example: Are current environmental and occupational standards adequate to prevent chronic lead intoxication? Is lead mobilized from the skeleton during pregnancy or lactation to cause fetal toxicity? Is lead mobilized from bone during menopause to cause neurotoxicity? What is the significance of genetic variation in determining susceptibility to lead? What is the contribution of lead to hypertension, renal disease, chronic neurodegenerative disease or declining sperm counts? Is chelation therapy effective in reducing body lead burden in persons with chronic overexposure to lead? (56).

\section{Frequency of Intoxication}

Lead toxicity is known to all cultures of the world, and efforts at reducing the prevalence of lead toxicity are common in industrialized countries. In France, more than $5 \%$ of adults and $2 \%$ of children aged 1-6 years have lead levels greater than $100 \mu \mathrm{g} / \mathrm{L}$ (16). The most recent National Health and Nutrition Examination Survey (NHANES) found that the prevalence of lead toxicity in children, i.e., lead levels greater than $100 \mu \mathrm{g} / \mathrm{L}$, ranged from $1.5 \%$ for upper income nonHispanic white children living in recently built houses in the suburbs, to a high of $36.7 \%$ for non-Hispanic black children residing in large cities (Anonymous, 2000). As was shown in a large retrospective study, in the Czech Republic the levels of lead are falling in the interval 1970-1980 (15.6 $\mu \mathrm{g} / \mathrm{L}$ vs. $6.6 \mu \mathrm{g} / \mathrm{L})$. In year 1985 concentration of $\mathrm{Pb}$ increased $(10.7 \mu \mathrm{gPb} / \mathrm{L})$ but subsequently decreased again $(1995-6.4 \mu \mathrm{g} / \mathrm{L})$. In year 1999 , it was $8.9 \mu \mathrm{g} / \mathrm{L}(8)$.

In the 70's, lead toxicity was a common illness, mostly for inner-city children. Lead encephalopathy was a common occurrence with thousands suffering permanent severe brain damage. Since the elimination of lead in gasoline, the average serum lead levels in the US has decreased from $120 \mu \mathrm{g} / \mathrm{L}$ in 1980 to $32 \mu \mathrm{g} / \mathrm{L}$ just 11 years later. The percentage of children with blood lead levels of $200 \mu \mathrm{g} / \mathrm{L}$ or more is now below $1 \%$. However, there is still a great variation within each city and region of the United States. Lead levels are much higher, for instance, in children living in pre-World War II housing. Lead poisoning continues to be a public health problem.

In adults, lead toxicity generally is the result of an occupational exposure, and estimated figures state that more than 800,000 American workers have significant lead exposure.

The exposure levels of $\mathrm{Pb}$ and expected health effects are monitored in the all forward countries. Resembling practice is pursue in the Czech Republic $(10,54)$.

\section{Mortality and Morbidity}

In humans, the acute ingestion of 15 grams of lead oxide has resulted in death. Survival generally depends on the adequacy of supportive care and the institution of chelation therapy. Chelation therapy combined with intensive therapy may reduce mortality rates from $65 \%$ to less than $5 \%$. However, morbidity continues to be high; close to $85 \%$ of patients who survive encephalopathy develop permanent and obvious neurologic severity, including seizures and cognitive deficits. Additional morbidity arises from the chronic effects of lead on the peripheral nervous system, the hematopoietic system, the renal system, and the gastrointestinal tract (46).

Recently, considerable attention has been given to the subtle effects of asymptomatic elevations of lead levels, which may have devastating effects on the population, such as reduction in cognitive abilities and intelligence quotient (IQ) and changes in personality. The blood lead level that is associated with observable effects in humans has not been determined. Levels that were thought to be safe have been proven toxic during early childhood. Reduced intelligence and poor school performance recently have been linked to blood lead concentrations as low as $1.2 \mu \mathrm{mol} / \mathrm{L}$, a level once thought to be safe $(38,55,57)$.

\section{Race Influence}

According to the latest NHANES study, black, nonHispanic, inner-city children living in old dilapidated buildings are at the highest risk for lead toxicity because of socioeconomic factors (43).

\section{Sex Influence}

Lead has adverse effects on follicle-stimulating hormone (FSH) and luteinizing hormone ( $\mathrm{LH})$ in both males and females (63). Lead has direct toxic effects on spermatogenesis, resulting in a decreased sperm count and an increase in the number of abnormal sperm $(4,48)$. Lead readily crosses the placenta and may exert adverse effects on the outcome of a pregnancy and the fetus. Lead poisoning has been associated with an increased risk of spontaneous abortion, preterm delivery, stillbirth, and increased incidence of infant mortality (37).

\section{Age Influence}

Infants and children are threaten by lead more than adults. They absorb lead more readily than adults and de- 
posit only $70 \%$ of the lead burden into bone, compared with $95 \%$ in adults. This deposit rate leaves $30 \%$ of the lead burden to be deposited in soft tissue, particularly the brain, kidneys, bone marrow, and liver. Even in blood level of 150 $\mu \mathrm{gPb} / \mathrm{L}$ appears a lot of unfavourable effects, retardation of mental and visceral development, reduced intelligence and immunity, decline of haemoglobin in red blood cells and peers anemia. Recent studies have shown that lead, even at relatively low levels of exposure, has the potential to harm not only the young and the occupationally-exposed, but also older people. Because they have been alive for a longer period of time, older adults have had more potential exposures to lead. They may have been exposed to lead while working in unregulated occupations, or they may have encountered more lead in the environment on a daily basis. Several large epidemiological studies have found that older people have higher blood and bone lead levels than younger adults (60). It was observed that lead can hibernate within bone for decades. Although lead within bone is of uncertain toxicity to bone tissue, conditions of bone resorption, such as osteoporosis, can cause bone lead to reenter the bloodstream where it can then re-expose the soft tissue, and, potentially, exert delayed deleterious effects. Evidence is emerging that blood and bone lead levels, reflecting relatively modest exposures, are associated with hypertension, renal insufficiency, and cognitive impairment. Physicians should be aware of potential past and present lead exposures among their older patients. In the future, treatment of osteoporosis may be undertaken not only to improve bone health but also to prevent mobilization of bone lead stores and subsequent toxicity (12).

\section{Medical Care and Treatment of Intoxication}

Intensive care monitoring is indicated for patients with suspected lead encephalopathy and during the initial phase intoxication treatment by intravenous chelation. Chelators are agents that are capable of binding to substances and forming a stable water-soluble compound that may be excreted easily. The indications for chelation therapy in the setting of lead poisoning depend on patient's age, symptoms, and blood lead levels $(33,34,52)$.

- The care of all patients begins with raising attention to the airway and breathing and size of circulation. Endotracheal intubation is indicated for the protection of the airway and for the provision of adequate oxygenation.

- Instantly the circulatory volume is reestablished and renal function is optimized, balance fluid infusions with fluid restriction to prevent further brain edema. Daily fluid requirements are based on calculated maintenance fluids.

- Maintain urine output at $0.5-1 \mathrm{ml} / \mathrm{kg} /$ hour. Urine output may be augmented by the intravenous infusion of mannitol. Mannitol is administered in a dose of $1-2 \mathrm{~g} / \mathrm{kg}$ of a $20 \%$ solution and a rate of $1 \mathrm{ml} / \mathrm{min}$.

- Convulsions and status epilepticus are treated in a conventional manner with benzodiazepines and other anti- convulsants, including phenobarbital and phenytoin. Patients with lead encephalopathy may require high doses of anticonvulsants for seizure control. Persistent status epilepticus may require neuromuscular blockade with EEG monitoring.

- Cerebral edema may be managed, preferably in consultation with a neurosurgery service, in a conventional manner with complete bed rest, sedation, and neuromuscular blockade. Elevation of the head of the bed, fluid restriction, hyperventilation (maintain pneumoxide at 25-30 $\mathrm{mm} \mathrm{Hg}$ ) and mannitol and/or other diuretics such as furosemide are recommended. Barbiturates may be used empirically for the prevention of seizures, which may exacerbate the brain edema.

- The most important aspect of therapy for lead toxicity is removal of the patient from the source of exposure and optimization of the nutritional status of the patient. Optimization of the stores of calcium, copper, and zinc in the body reduces lead absorption from the gastrointestinal tract.

- Decontamination may be accomplished with gastric lavage if the ingestion is recent or with whole bowel irrigation, using a polyethylene glycol solution, when the presentation is remote. Whole bowel irrigation is performed with polyethylene glycol solution at a rate of $100-500 \mathrm{ml} / \mathrm{h}$ in children and $500-2000 \mathrm{ml} / \mathrm{h}$ in adults until the abdominal x-ray is clear.

- Chelation therapy is indicated as soon as the diagnosis of severe lead toxicity is considered. Do not delay chelation therapy until a definitive blood lead level is obtained. Chelation functions by binding with lead and forming a water-soluble complex that may be excreted in urine. The efficacy of treatment may be monitored by postchelation decreases in blood lead concentrations, the finding of increased urine lead excretion or by the normalization of circulating delta-aminolevulinic acid dehydrase levels.

- Currently, three agents are recommended for the chelation of lead. Dimercaprol (BAL) and $\mathrm{Ca}-\mathrm{Na}_{2}-\mathrm{EDTA}$ are administered parenterally and succimer (dimercaptosuccinic acid [DMSA]) is administered orally. D-penicillamine, which historically enjoyed widespread use as an oral agent, currently only is recommended for persistent lead toxicity despite maximal therapy with the above chelating agents. An additional drug, 2,3-dimercaptopropane-1-sulfonic acid (DMPS) currently is used in Europe and Asia.

- Parenteral chelation is indicated in both adults and children exhibiting signs of lead encephalopathy, including severe headaches, seizures, altered mental status, and coma. Lead levels exceeding $700 \mu \mathrm{g} / \mathrm{L}$ in children and $1000 \mu \mathrm{g} / \mathrm{L}$ in adults also require parenteral chelation, even in the absence of symptoms. Lead levels from $450-700 \mu \mathrm{g} / \mathrm{L}$ in asymptomatic children and 700-1000 $\mu \mathrm{g} / \mathrm{L}$ in asymptomatic adults may be treated with oral chelation therapy. Lead levels below $450 \mu \mathrm{g} / \mathrm{L}$ in asymptomatic children and below $700 \mu \mathrm{g} / \mathrm{L}$ in asymptomatic 
adults usually only require removal of the patient from the environment in which they were exposed to the lead.

\section{Further Necessary Care}

Chelation therapy for lead encephalopathy and asymptomatic high-blood lead concentrations is continued for 5 days and requires the concomitant use of both BAL and $\mathrm{Ca}-\mathrm{Na}_{2}$-EDTA. As lead initially and primarily is mobilized from the soft tissues and only a fraction is mobilized from the bone, soft tissue and blood lead content may rebound after cessation of therapy because these lead pools equilibrate. A second course of chelation therapy may be administered 2 days after therapy is discontinued if the patient's symptoms persist or reappear in the face of rebound increases in blood lead levels $(>500 \mu \mathrm{g} / \mathrm{L})$. A third course of chelation rarely may be required. In this case, a chelator-free interval of 1 week is recommended prior to initiation of the third course (29).

\section{References}

1. Aicheson A. A History of Metals, 2 Vols., New York, Interscience, 1960

2. Anonymous. Blood lead levels in young children - United States and selected states, 1996-1999. MMWR 2000;49: 1133-1137. Available at: http://www.cdc.gov/ $/ \mathrm{mmwr} /$ preview/mmwrhtml/mm4950a3.htm

3. Anttila A, Heikkila P, Pukkala E, Nykyri E, Kauppinen T, Hernberg S, Hemminki $\mathrm{K}$. Excess lung cancer among workers exposed to lead. Scand J Work Environ Health 1995:21:460-9.

4. Apostoli P, Kiss P, Porru S, Bonde JP, Vanhoorne MMale reproductive toxicity of lead in animals and humans. ASCLEPIOS Study Group. Occup Environ Med 1998;55:364-74.

5. Auerbach AD. Fanconi anemia. Dermatol Clin 1995;13:41-9.

6. Azar A, Trochimowicz HJ, Maxfield ME. Review of lead studies in animals carried out at Haskell Laboratory - Two year feeding study and response to hemorrhage study. In: Barth D, Berlin A, Engel R, Recht P. Smeets J, (Ed). Environmental health aspects of lead: Proceedings International Symposium, October 1972, Amsterdam, The Netherlands. Commission of the European Communities, Luxemberg, 1973:199-208.

7. Babčan J, Ševc J. Lead (Pb II) in systems with organic compounds. Ekológia 1996;15:243-50.

8. Beneš B, Spěváčkova $\mathrm{V}$, Čejchanová $\mathrm{M}$, Šmíd J, Švandová E. Retrospective study of concentration levels of $\mathrm{Pb}, \mathrm{Cd}, \mathrm{Cu}$ and $\mathrm{Se}$ in serum of the Czech population in time period 1970-1999. Cent Eur J Public Health 2001;9:190-5.

9. Berglund M, Akesson A, Bjellerup P, Vahter M. Metal-bone interactions. Toxicol Lett 2000;112-113:219-25.

10. Bláha K, Bencko V, Cikrt M. Exposure to lead and human health in the Czech Republic. Cent Eur J Public Health 1996;4:233-41.

11. Bouton CM, Hossain MA, Frelin LP, Laterra J, Pevsner J. Microarray analysis of differential gene expression in lead-exposed astrocytes. Toxicol Appl Pharmaco 2001; 176:34-53

12. Carrington CD, Sheehan DM, Bolger PM. Hazard assessment of lead. Food Addit Contam 1993; 10:325-35.

13. Community Assessment Unit, Bureau of Environmental Health Assessment, Massachusetts Department of Public Health. Risk factor information for selected cancer types, 2001. Available at: http://www.state.ma.us/dph/beha/cau/ /reports/swnas/appc_brain.pdf

14. Cooper WC. Mortality among employees of lead battery plants and lead producing plants, 1947-1980. Scand J Work Environ Health 1985;11:331-45.

15. Cooper WC, Gaffey WR. 1975. Mortality of lead workers. In: Proceedings of the 1974 Conference on Standards of Occupational Lead Exposure, Cole JF (Ed.), Washington, DC. J Occup Med 1974;17:100-107.

16. De Haro L, Prost N, Gambini D et al. Lead poisoning in adults. Experience of the Poison Control Center of Marseille from 1993 to 2000 (Article in French). Presse Med 2001;30:1817-20.

17. Diamond GL, Goodrum PE, Felter SP, Ruoff WL. Gastrointestinal absorption of metals. Drug Chem Toxicol 1998;21:223-51.

18. Dingwall-Fordyce I, Lane RE. A follow-up study of lead workers. Br J Ind Med 1963;20:313-5

19. Fu H, Boffetta P. Cancer and occupational exposure to inorganic lead compounds: a meta-analysis of published data. Occup Environ Med 1995;52:73-81.
20. Gijon E, Cartas L, Garcia X. Lead acetate action on anaphylactic response of guinea pig smooth muscle. Proc West Pharmacol Soc 2001;44:145-6.

21. Gmerek DE, McCafferty MR, O’Neill KJ, Melamed BR, O'Neill JJ. Effect of inorganic lead on rat brain mitochondrial respiration and energy production. J Neurochem 1981;36:1109-13.

22. Goldstein GW. Brain capillaries: a target for inorganic lead poisoning. Neurotoxicology $1984 ; 5: 167-75$.

23. Gressens P, Mesples B, Sahir N, Marret S, Sola A. Environmental factors and disturbances of brain development. Semin Neonatol 2001;6:185-94.

24. Jover R, Lindberg RL, Meyer UA. Role of heme in cytochrome P450 transcription and function in mice treated with lead acetate. Mol Pharmacol 1996; 50: $474-81$

25. Kasprzak KS, Hoover KL, Poirier LA. Effects of dietary calcium acetate on lead subacetate carcinogenicity in kidneys of male Sprague-Dawley rats. Carcinogenesis. 1985:6:279-82.

26. Kohlmeier RE. Chronic lead poisoning: induced psychosis in an adult? Am J Forensic Med Pathol 2002;23:101

27. Koller LD, Kerkvliet NI, Exon JH. Neoplasia induced in male rats fed lead acetate, ethyl urea and sodium nitrate. Toxicol Pathol 1986:13.50-7.

28. Lanphear BP, Dietrich K, Auinger P, Cox C. Cognitive deficits associated with blood lead concentrations $<10 \mu \mathrm{g} / \mathrm{dL}$ in US children and adolescents. Public Health Rep 2000;115:521-9.

29. Lee BK, Schwartz BS, Stewart W, Ahn KD. Provocative chelation with DMSA and EDTA: evidence for differential access to lead storage sites. Occup Environ Med 1995;52:13-9

30. Loghman-Adham M. Renal effects of environmental and occupational lead exposure. Environ Health Perspect 1997;105:928-39.

31. Lu H, Guizzetti M, Costa LG. Inorganic lead activates the mitogen-activated protein kinase kinase-mitogen-activated protein kinase-p90(RSK) signaling pathway in human astrocytoma cells via a protein kinase C-dependent mechanism. J Pharmacol Exp Ther 2002;300:818-23.

32. Lu H, Guizzetti M, Costa LG. Inorganic lead stimulates DNA synthesis in human astrocytoma cells: role of protein kinase Calpha. J Neurochem 2001; 78:590-9.

33. Mandelbaum DE. Chelation therapy in children exposed to lead. N Engl J Med 2001;345:1213.

34. Markowitz M. Lead poisoning. Pediatr Rev 2000;21:327-35

35. Moore MR, Meredith PA. The carcinogenicity of lead. Arch Toxicol 1979;42:87-94

36. Mushak P. New directions in the toxicokinetics of human lead exposure Neurotoxicology 1993;14:29-42.

37. Nashashibi N, Cardamakis E, Bolbos G, Tzingounis V. Investigation of kinetic of lead during pregnancy and lactation. Gynecol Obstet Invest 1999;48:158-62.

38. Needleman HL. The neurobehavioral consequences of low lead exposure in childhood. Neurobehav Toxicol Teratol 1982;4:729-32.

39. Nelson DJ, Kiremidjian-Schumacher L, Stotzky G. Effects of cadmium, lead, and zinc on macrophage-mediated cytotoxicity toward tumor cells. Environ Res 1982;28:154-63

40. Nolan CV, Shaikh ZA. Lead nephrotoxicity and associated disorders: biochemical mechanisms. Toxicology 1992;73:127-46.

41. O'Halloran K, Spickett JT. The interaction of lead exposure and pregnancy. Asia Pac J Public Health 1992-93;6:35-9.

42. Pappas CL, Quisling RG, Ballinger WE, Love LC. Lead encephalopathy: symp toms of a cerebellar mass lesion and obstructive hydrocephalus. Surg Neurol 1986:26:391-4.

43. Pirkle JL, Kaufmann RB, Brody DJ, Hickman T, Gunter EW, Paschal DC. Exposure of the U.S. population to lead, 1991-1994. Environ Health Perspect 1998; 106:745-50.

44. Preuss HG. A review of persistent, low-grade lead challenge: neurological and cardiovascular consequences. J Am Coll Nutr 1993;12:246-54.

45. Rasmussen K, Gilkou T. Health surveillance of workers exposed to lead in the County of Arhus (Article in Danish). Ugeskr Laeger 1991;153:975-8.

46. Rogan WJ, Dietrich KN, Ware JH et al. Treatment of Lead-Exposed Children Trial Group. The effect of chelation therapy with succimer on neuropsychological development in children exposed to lead. N Engl J Med 2001;344:1421-6.

47. Rosen JF, Zarate-Salvador C, Trinidad EE. Plasma lead levels in normal and leadintoxicated children. J Pediatr 1974xicated children. J Pediatr 1974e to lead and male fertility. Int J Occup Med Environ Health 2001;14:219-22.

49. Sakai T. Biomarkers of lead exposure. Ind Health 2000:38:127-42.

50. Schwartz BS, Stewart WF, Bolla KI et al. Past adult lead exposure is associated with longitudinal decline in cognitive function. Neurology 2000; 55: 1144-1145. Erratum in Neurology 2001;56:283

51. Selevan SG, Landrigan PJ, Stern FB, Jones JH. Mortality of lead smelter workers. Am J Epidemiol 1985;122:673-83.

52. Shannon M. Lead poisoning treatment - a continuing need (commentary). J Toxicol Clin Toxicol 2001;39:661-3.

53. Smith CM, Wang X, Hu H, Kelsey KT. A polymorphism in the delta-aminolevulinic acid dehydratase gene may modify the pharmacokinetics and toxicity of lead. Environ Health Perspect 1995;103:248-53 
54. Šmerhovský Z, Černá L, Cikrt M, Černá M. Biomonitoring of lead exposure in the Czech Republic. Int J Occup Med Environ Health 2001:14:157-62.

55. Thatcher RW, Lester ML, McAlaster R, Horst R. Effects of low levels of cadmium and lead on cognitive functioning in children. Arch Environ Health 1982;37:159-66.

56. Todd AC, Wetmur JG, Moline JM, Godbold JH, Levin SM, Landrigan PJ Unraveling the chronic toxicity of lead: An essential priority for environmental health. Environ Health Perspect 1996;104(Suppl 1):141-6.

57. Tuthill R. Hair lead levels related to children's classroom attention-deficit behavior. Arch Environ Health 1996;51:214-20.

58. Van Esch GJ, Kroes R. The induction of renal tumors by feeding of basic lead acetate to mice and hamsters. Br J Cancer 1969;23:265-71.

59. Vega J, Contreras A, Rios E, Marchetti N, Agurto M. Lead exposure and its effects on child health (Article in Spanish) Rev Chil Pediatr 1990;61:154-60.

60. Vig EK, Hu H. Lead toxicity in older adults. J Am Geriatr Soc 2000;48:1501-6.

62. Vig PJ, Pentyala SN, Chetty CS, Rajanna B, Desaiah D. Lead alters inositol polyphosphate receptor activities: protection by ATP. Pharmacol Toxicol 1994; 75:17-22.

63.Vivoli G, Fantuzzi G, Bergomi M et al. Relationship between low lead exposure and somatic growth in adolescents. $J$ Expo Anal Environ Epidemiol 1993;3(Suppl 1):201-9.
64. Warren C. Brush With Death. A Social History of Lead Poisoning. Johns Hopkins Univ Press, 2001

65. Warren MJ, Cooper JB, Wood SP, Shoolingin-Jordan PM. Lead poisoning, haem synthesis and 5-aminolaevulinic acid dehydratase. Trends Biochem Sci 1998;23:217-21.

Submitted September 2002.

Accepted March 2003.

Prof. RNDr. Jiř̌ Patočka, DrSc., Purkyně Military Medical Academy,

Department of Toxicology, 50001 Hradec Králové, Czech Republic. e-mail: patocka@pmfhk.cz 